\title{
Estudo do Uso da Carbonatação Acelerada em Pastas de Cimento Portland Usando Resíduos de Diatomita Recuperados
}

\section{Study of the Use Of Accelerated Carbonation in Cement Portland Pastes Using Recovered Diatomite Waste}

\author{
${ }^{1}$ Rosane Olivo Menegon. ${ }^{2}$ Alex Neves Junior \\ ${ }^{1}$ Mestranda do Programa de Pós-Graduação em Engenharia de Edificações e Ambiental \\ da Universidade Federal de Mato Grosso (rosane.olivo@gmail.com) \\ ${ }^{2}$ Professor Doutor do Programa de Pós-Graduação em Engenharia de Edificações e Ambiental \\ da Universidade Federal de Mato Grosso (alexnevesjr@gmail.com)
}

\begin{abstract}
RESUMO: Um dos resíduos gerado nas indústrias cervejeiras é a pasta de diatomita produzida na etapa de filtração e clarificação da cerveja, apresentando vida útil muito curta, pois ao ficar saturada com material orgânico no processo de fermentação da cerveja, inviabiliza a sua reutilização como material filtrante. Em virtude de sua alta capacidade de absorção, observou-se o possível potencial de utilização do resíduo dentro de produtos à base de cimento Portland. Assim, objetiva-se neste trabalho avaliar o efeito da ação da carbonatação acelerada em matrizes cimentícias com substituição de terra diatomácea, em especial o impacto nas propriedades térmicas das pastas. Foram produzidas pastas cimentícias com água / materiais cimentícios (a/mc) de 0,7. Um tratamento de carbonatação acelerada foi aplicado nas amostras para investigar o efeito sobre a resistência à compressão. Para a caracterização, foram realizadas análises térmicas diferenciais não convencionais (NCDTA), calorimetria isotérmica, teste de compressão e teste de Vicat. A carbonatação acelerada promoveu elevação em média de 67,50\% na compressão em relação a pasta de controle. Os melhores resultados foram obtidos nas pastas com 10 e $30 \%$, de substituição de diatomita. Pelo teste de calorimetria isotérmica, no período de aceleração as pastas controle apresentaram maior energia térmica que as pastas com diatomita. No entanto, após o maior pico de hidratação e durante o período de desaceleração, as pastas com diatomita apresentaram maior energia térmica que as controles, mostrando potencial de atividade pozolânica. Conclui-se que a diatomita proveniente das indústrias cervejeiras é um resíduo passível de ser utilizado nos materiais de construções, pois as pastas produzidas com sua incorporação além de reduzir a emissão de $\mathrm{CO}_{2}$, fornecem uma alternativa para reciclar este material degradado, promovendo uma destinação adequada e reduzindo os impactos no meio ambiente.
\end{abstract}

Palavras chave: Calorimetria isotérmica; Carbonatação acelerada, Diatomita, Ciência dos Materiais.

ABSTRACT: The diatomite sludge is a residue from the beverage industry, after filtering process. In the stages of filtering, the diatomite presents a very short lifetime, because it becomes saturated with organic material, from the fermenting process of the beverages, not making possible to use it as filtering material. Due to this high saturation stage, it was observed the potential use of the diatomite residue within cement-based materials. Thus, the objective of this work was to evaluate the effect of the accelerated carbonation curing in cementitious materials using recovered diatomite waste. Were produced cementitious pastes with water/cementitious materials (w/cm) equal to 0,7. All the pastes were set to a normal consistency, according to the required Brazilian standard method. A accelerated carbonation treatment was applied to investigate the effect on the compressive strength.For the characterization, were performed Non-convencional Differential Thermal Analysis (NCDTA), isothermal calorimetry, compression test and Vicat analysis test. The carbonation test showed an increase of the mechanical resistance in the pastes with 10 and 30\%. By the isothermal calorimetry test, until the acceleration period, the control pastes presented a higher thermal energy than the pastes with diatomite. However, after the higher hydration peak and during the deceleration period, the pastes with diatomite presented the higher thermal energy than the control pastes, showing potential pozzolanic activity. The heat of hydration for the control pastes was higher than all the diatomite pastes. The results showed that the use of recovered diatomite waste is a feasible option to manufacture green construction materials, with low carbon footprint and reliable thermal and mechanical properties.

Keywords: Isothermal calorimetry; Accelerated carbonation curing, Diatomite, Mechanical properties. 
Menegon, Rosane O; Neves Junior, Alex; Estudo do Uso da Carbonatação Acelerada em Pastas de Cimento Portland Usando Resíduos de Diatomita Recuperados. E\&S - Engineering and Science, (2018), 7:1

\section{INTRODUÇÃO}

Numa apreciação geral, pode-se dizer que os resíduos sólidos devem ser estudados desde sua geração até sua disposição final. Este ciclo apresenta implicações como, o descarte inadequado de produtos que poderiam ser reutilizados, gerando desta forma poluição e contaminação ambiental (SORBAZO e MARIN, 2010). Uma solução a ser aplicada para que as futuras gerações possam usufruir o que o meio ambiente ainda poderá oferecer, seria a reutilização dos resíduos gerados pelas indústrias ou pelas próprias pessoas, evitando desta forma a necessidade de captação de recursos naturais e seus derivados.

Um resíduo disposto no meio ambiente pelas indústrias cervejeiras é a pasta de diatomita ou terra diatomácea. Esta pasta é formada pelo processo de filtração da cerveja. Este material é proveniente de jazidas naturais e é utilizado nos sistemas filtrantes, devido sua capacidade de absorção pela porosidade que os grânulos apresentam. Quando aplicada na etapa de filtração e clarificação da cerveja a terra diatomácea apresenta uma vida útil muito curta, pois satura-se com material orgânico, derivado do processo fermentação da cerveja, inviabilizando a sua reutilização como material filtrante (GOULART et al., 2011).

Devido esta alta capacidade de absorção, observou-se uma possível utilização do resíduo de terra diatomácea dentro de produtos a base de cimento Portland. Será verificada a possibilidade de aumentar a capacidade de captura de $\mathrm{CO}_{2}$, via carbonatação de matrizes cimentícias com substituição de terra diatomácea. Ao mesmo tempo em que é possível melhorar as propriedades do material, a reação de carbonatação pode ser aproveitada como alternativa ambiental para o sequestro do $\mathrm{CO}_{2}$. Não foram encontrados trabalhos que se atentem a reutilização deste material em produtos de construção civil e sua aplicação na captura de $\mathrm{CO}_{2}$.

A hidratação do cimento Portland evolui no decorrer do tempo, aos 28 dias de cura cerca de 70-80\% de grau de hidratação são atingidos. A hidratação da pasta é responsável pela reação entre cimento e água que dá origem às características de pega e endurecimento.

As propriedades do cimento Portland estão diretamente associadas às concentrações de suas fases constituintes, principalmente a alita, a belita, a fase ferrítica e o aluminato. A alita, de composição $3 \mathrm{CaO}^{-\mathrm{SiO}_{2}}$ e abreviada por $\mathrm{C}_{3} \mathrm{~S}$, deve ser o constituinte predominante do clínquer pois é sua reação de hidratação que define a resistência mecânica ao cimento após a cura. A belita, composta por $2 \mathrm{CaO} . \mathrm{SiO}_{2}$ e abreviada por $\mathrm{C}_{2} \mathrm{~S}$, está presente como o primeiro complexo de cal e sílica produzido no aquecimento e, sendo mais estável a baixas temperaturas que o $\mathrm{C}_{3} \mathrm{~S}$, volta a se formar no resfriamento. $\mathrm{O}$ aluminato encontra-se principalmente na forma de $3 \mathrm{CaO} . \mathrm{Al}_{2} \mathrm{O}_{3}$, abreviado por $\mathrm{C}_{3} \mathrm{~A}$, enquanto a ferrita aparece como componente na forma $4 \mathrm{CaO} . \mathrm{Al}_{2} \mathrm{O} 3 . \mathrm{Fe}_{2} \mathrm{O}_{3}$, abreviada por $\mathrm{C}_{4} \mathrm{AF}$ (TENÓRIO et al., 2003).

Thomas e Jennings (2014) descrevem o hidróxido de cálcio, também conhecido pelo seu nome mineral de portlandita, formado a partir do silicato tricálcico conhecido como $\mathrm{C} 3 \mathrm{~S}$ ou alita e, em menor extensão, o silicato bicálcico descrito como $\mathrm{C} 2 \mathrm{~S}$ ou belita através das reações demonstradas nas Equações 1 e 2.

$$
\begin{gathered}
C_{3} S+(1.3+x) H \rightarrow C_{1.7} S H_{x}+1.3 C H \\
C_{2} S+(0.3+x) H \rightarrow C_{1.7} S H_{X}+0.3 C H
\end{gathered}
$$

Segundo Rubert (2015), a Figura 1 representa a formação das principais fases de hidratação do cimento. $\mathrm{O}$ composto utilizado para representar a hidratação do cimento é o $\mathrm{C}_{3} \mathrm{~S}$, devido à reação de $\mathrm{C}_{3} \mathrm{~A}$ ser muito intensa, quando em contato com água. Ademais ressalta-se como a gipsita $\left(\mathrm{CaSO}_{4} \cdot 2 \mathrm{H}_{2} \mathrm{O}\right)$ é adicionada para retardar a reação do aluminato. 
Figura 1- Formação das fases de hidratação do cimento

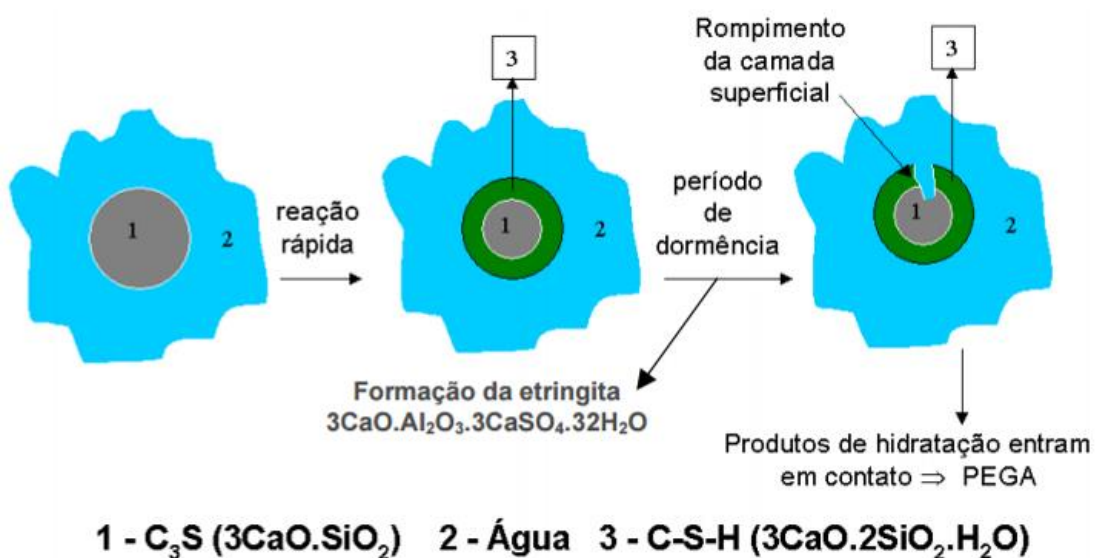

Fonte: Adaptado de Brehm (2004)

À medida que o gel de hidrato de cálcio-silicato C-S-H, cresce para fora das partículas de cimento, ele não assume a forma de uma fase sólida monolítica, mas em vez disso desenvolve um sistema interno de poros minúsculos, chamados cristais. O C-S-H não é apenas o produto de reação mais abundante, mas também é responsável pela maioria das propriedades em uma pasta de cimento (THOMAS e JENNINGS, 2014).

Num primeiro momento, o $\mathrm{C}_{3} \mathrm{~S}$ entra em contato com a água formando uma camada de CS-H em torno dos grãos de cimento, devido a isto há um retardo na reação de hidratação. Nesta primeira fase ocorre formação da etringita que é um produto resultante dos processos de hidratação dos aluminatos e que atinge seu pico máximo em 24 horas após o inicio da hidratação do cimento. Posteriormente, verifica-se que a concentração de aluminatos se eleva novamente devido a renovação de hidratação do $\mathrm{C}_{3} \mathrm{~A}$ e do $\mathrm{C}_{4} \mathrm{AF}$, sendo assim a etringita se transforma em monossulfato (BREHM, 2004).

Para desenvolver a resistência mecânica e os compósitos presentes em uma pasta cimentícia, alguns compostos são responsáveis por esta reação que são especificamente o $\mathrm{C}_{3} \mathrm{~S}$ e o $\mathrm{C}_{2} \mathrm{~S}$, em seguida ocorre a formação do hidróxido de cálcio $\left(\mathrm{Ca}(\mathrm{OH})_{2}\right)$ ou portlandita que cristaliza após saturação da agua de mistura da pasta, liberando calor.

A reação química em que os produtos de hidratação alcalinos do cimento Portland, chamase carbonatação, e o produto principal é o hidróxido de cálcio $\left(\mathrm{Ca}(\mathrm{OH})_{2}\right)$, onde o mesmo reage com o $\mathrm{CO}_{2}$ em um processo de dissolução/precipitação, gerando produtos à base de carbonato e gel de sílica (NEVES JUNIOR et al., 2017).

No concreto, a carbonatação acontece pela penetração do dióxido de carbono nos poros com água, comumente chamados "frente de carbonatação". A reação química entre o $\mathrm{CO}_{2}$ dissolvido na água e os produtos de hidratação do cimento, tais como o hidróxido de cálcio, resultam em carbonato de cálcio e água (DAMIN, 2013). Se os poros estiverem secos não ocorre dissociação iônica. Esse fenômeno físico-químico que reage com a presença de gases ácidos, que estão no ambiente juntamente com os produtos alcalinos presentes nas reações de hidratação do cimento, formando produtos com $\mathrm{pH}$ de precipitação inferior a 9, sendo prejudiciais para as estruturas de concreto armado.

A carbonatação natural é um processo lento devido ao baixo teor de $\mathrm{CO}_{2}$ da atmosfera, da ordem de $0,03 \%$ em volume do ar ambiente, em alguns materiais a base de cimento a carbonatação pode ocorrer após vários anos ou décadas. 
A carbonatação é conhecida por melhorar a dureza superficial, resistência e durabilidade dos produtos à base de cimento por refinamento da matriz de pasta de cimento. A carbonatação em produtos à base de Cimento Portland pode ser definida como uma reação entre o $\mathrm{CO}_{2}$ dissolvido em água e o produto de hidratação do cimento de $\mathrm{Ca}(\mathrm{OH})_{2}$ na água dos poros (KOUA, ZHANA e POON, 2014).

De acordo com Werle, Kazmierczak e Kulakowski (2011), a reação básica de carbonatação decorre da combinação do $\mathrm{CO}_{2}$, que se encontra dissociado em meio aquoso, dentro dos poros do concreto, com o $\mathrm{Ca}(\mathrm{OH})_{2}$, que também está neste mesmo ambiente. Essa interação entre os elementos resulta na formação de $\mathrm{CaCO}_{3}$ (carbonato de cálcio) e $\mathrm{H}_{2} \mathrm{O}$ (água).

A profundidade e a velocidade de carbonatação são influenciadas de acordo com a porosidade e o $\mathrm{pH}$ do concreto. A dissolução do $\mathrm{CO}_{2}$ provoca a redução do $\mathrm{pH}$ da solução presente nos poros, com isso a dissolução do $\mathrm{Ca}(\mathrm{OH})_{2}$ ocorre para restabelecer a alcalinidade do meio, seguido de sua difusão das regiões de maior alcalinidade para as de menor alcalinidade. Neves Junior (2014) descreve que a captura de $\mathrm{CO}_{2}$ através da carbonatação de materiais cimentícios durante a sua produção e industrialização, e considera que existe um potencial líquido de sequestro entre 0,98 a 1,8 milhão de toneladas de $\mathrm{CO}_{2}$ anuais com uma eficiência entre $84 \%$ e $87,1 \%$ no processo de captura.

Os produtos a base de cimento Portland, como blocos e placas, que não utilizam reforço de

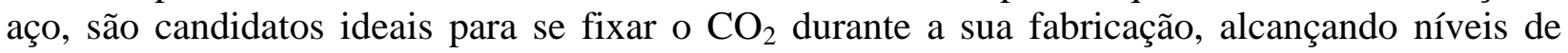
resistência satisfatórios com poucas horas de tratamento em relação à cura convencional aos 28 dias e reaproveitando ao mesmo tempo o $\mathrm{CO}_{2}$ emitido durante o processo produtivo (NEVES JUNIOR, 2014).

Além da viabilidade demostrada de se capturar o $\mathrm{CO}_{2}$ durante o processo produtivo de materiais cimentícios, existe ainda o aspecto econômico a se considerar ao se medir a quantidade do $\mathrm{CO}_{2}$ efetivamente absorvido, em vista dos créditos de carbono que podem ser obtidos com a implementação deste processo (NEVES JUNIOR, 2014).

A terra diatomácea depois de calcinada torna-se um material sem resíduos orgânicos podendo ser reutilizado para produção de novos materiais. Assim, objetiva-se com esta pesquisa verificar a ação da carbonatação acelerada em matrizes cimentícias com substituição de terra diatomácea, bem como qual ação a adição de diatomita desencadeia nas propriedades térmicas das pastas.

\section{MATERIAIS}

Para o desenvolvimento desta pesquisa, utilizou-se um resíduo de terra diatomácea onde a mesma foi substituída em relação a massa inicial de cimento. Os percentuais de substituição para este estudo foram de $10 \%, 20 \%$ e $30 \%$ e uma pasta referência. Seu cálculo se deu devido ao volume necessário para o preenchimento dos corpos de prova, sempre considerando a referência como base de cálculo.

\section{1 Água}

A água que foi utilizada é proveniente da rede de abastecimento municipal de Cuiabá-MT, tendo como gestora a CAB Cuiabá (Companhia de Águas Brasil), sendo sempre utilizada do mesmo ponto de coleta e temperatura ambiente. 
Menegon, Rosane O; Neves Junior, Alex; Estudo do Uso da Carbonatação Acelerada em Pastas de Cimento Portland Usando Resíduos de Diatomita Recuperados. E\&S - Engineering and Science, (2018), 7:1

\subsection{Cimento}

O cimento Portland utilizado para fabricação das pastas durante os ensaios foi o CP II F 32, disponível na Universidade Federal de Mato Grosso (UFMT). O material, ainda lacrado em sua embalagem original, foi disposto dentro de um saco plástico, fechado sempre, para evitar a entrada de umidade e alteração de suas características originais e armazenado no Laboratório de Materiais de Construção Civil da UFMT.

\section{$2.3 \mathrm{CO}_{2}$}

$\mathrm{O}$ dióxido de carbono $\mathrm{CO}_{2}$ utilizado na carbonatação das atrizes cimentícias com pureza de $99 \%$, armazenado em cilindro de aço contendo $10 \mathrm{~m}^{3}$ de gás, está instalado na câmera de $\mathrm{CO}_{2}$, que fica no Laboratório de Farmacologia do curso de Medicina da UFMT, com uso especifico para as analises referentes a pastas cimentícias.

\subsection{Terra Diatomácea}

A amostra em forma de torta foi doada por uma indústria de bebidas localizada região de estudo. Esta amostra é proveniente do processo de filtração e clarificação da cerveja. A coleta foi feita em caçambas de descarte de diatomita abaixo do filtro da cervejaria.

\section{MÉTODOS}

Com a torta de terra diatomácea proveniente da indústria cervejeira, foi executado a secagem em estufa FANEM modelo 315 SE, locada no laboratório de Mecânica dos Solos da UFMT, primeiramente, sendo a mesma feita em 3 etapas de secagem a $105^{\circ} \mathrm{C}$. A secagem das amostras foi feita através da disposição da torta em duas bandejas de alumínio, e sendo feita a homogeneização no intervalo de uma hora, para garantir a secagem de forma homogênea.

Em seguida utilizando equipamento Mufla, localizada no Laboratório de Análises FísicoQuímicas de Água e Resíduos (LAFQAR) do departamento de Engenharia Sanitária e Ambiental da UFMT, sendo seu modelo e marca Linn Elektro Therm AK-MODEL, foi feito o segundo tratamento térmico com temperatura de $700^{\circ} \mathrm{C}$ para purificação da amostra e queima da matéria orgânica, em que a queima foi repetida 3 vezes para que houvesse a garantia da eliminação de toda matéria orgânica.

A amostra de terra diatomácea seca e livre de matéria orgânica segue para o processo de peneiramento manual, para que seja homogeneizada e então adicionada as pastas cimentícias. Para fazer este processo foram utilizadas as peneiras padronizadas pela NBR 7181 (ABNT, 2016), sendo a terra diatomácea utilizada toda passante na $0,075 \mathrm{~mm}$, classificando este material como fino.

\subsection{Análise Térmica Diferencial não Convencional}

No método Non-convencional Differential Thermal Analysis (NCDTA), não se utilizam dispositivos externos de controle de temperatura, seu meio de operação é semi-adiabático e a temperatura medida é consequência dos efeitos térmicos espontâneos promovidos pelas reações de hidratação do cimento (NEVES JUNIOR, 2014).

O ensaio de NCDTA foi realizado no Laboratório de Estruturas da UFMT. Sendo esse ensaio dividido em cinco estágios, montou-se um sistema para a realização do NCDTA, conforme desenho esquemático na Figura 2, caracterizando a primeira etapa. 


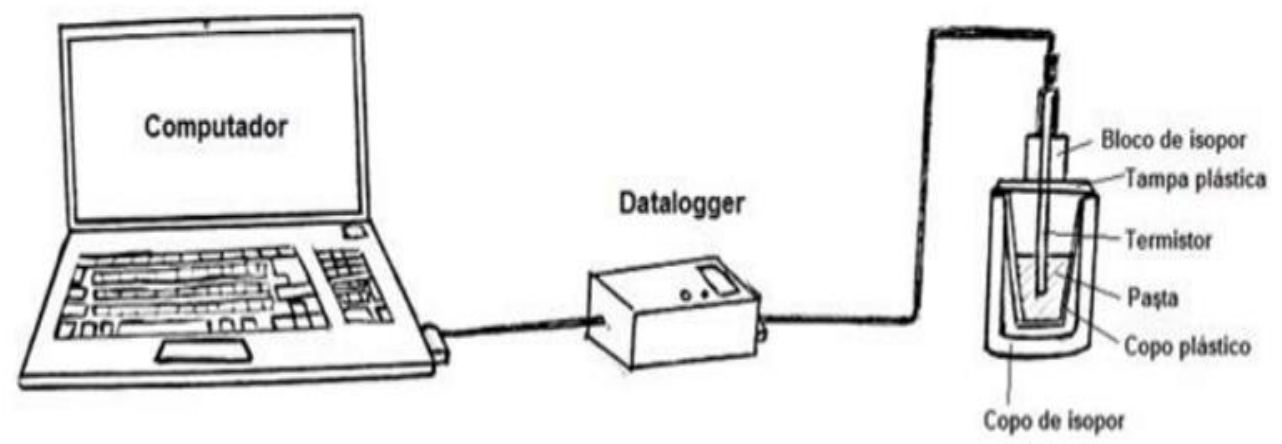

Fonte: NEVES JUNIOR, 2014

O sistema é composto por: duas placas de isopor como base, copos isolantes de isopor, copos de plástico com tampas, cubos de isopor para isolamento das pastas do meio externo, termistores, datalogger LAB-PRO para fazer a interface entre o termistor e o computador e um computador.

No segundo estágio foi confeccionada uma pasta de referência endurecida com a finalidade de ser utilizada durante a terceira etapa, para registrar apenas as variações de temperatura ambiente. Foram misturados, em recipiente plástico, 200g de cimento Portland com um fator água/material cimentíceo $(\mathrm{a} / \mathrm{mc})$ de 0,7 .

Inicialmente de forma subjetiva foi adotada relação agua cimento 0,7 em função da trabalhabilidade visual das pastas. Para o terceiro estagio foram confeccionadas quatro pastas diferentes entre si. A escolha das relações água/material cimentíceo foram determinadas inicialmente pela trabalhabilidade do material na sua maior concentração de adição de diatomita, sendo o resultado deste ensaio empírico o valor da relação a/mc como um único valor de 0,7 . Os teores de substituição de cimento por diatomita eram de 10, 20, e $30 \%$.

A partir da entrada da primeira pasta no sistema, a CP2-D-0, as variações de temperaturas começaram a ser registradas mantendo uma frequência de 3 medidas por minuto. Após aproximados três dias de dados coletados, os mesmos foram extraídos do computador e inseridos em uma planilha no software Microsoft Excel 2010® para serem tratados.

Nesse trabalho será utilizada a seguinte nomenclatura:

- CP: Corpo de Prova;

- CONT: Controle;

- D0, D10, D20, D30: Teor de substituição de Diatomita, conforme o exemplo a seguir D10 diatomita $10 \%$; e,

- CP-D-0: para uma pasta endurecida com teor de agua/material cimentício 0,7.

Para que $\mathrm{o} \mathrm{CO}_{2}$ possa ter sua maior absorção no interior das pastas, é necessário que as mesmas estejam em estado fresco e que possam ser desmoldadas das formas. A determinação do tempo de desmoldagem foi obtida através dos gráficos de NCDTA, em que observou-se a queda de temperatura e assim iniciando o tempo de fim de pega. 
Menegon, Rosane O; Neves Junior, Alex; Estudo do Uso da Carbonatação Acelerada em Pastas de Cimento Portland Usando Resíduos de Diatomita Recuperados. E\&S - Engineering and Science, (2018), 7:1

\subsection{Carbonatação Acelerada}

Os moldes para os corpos de provas possuem forma cilíndrica com $2,5 \mathrm{~cm}$ de diâmetro e 5 $\mathrm{cm}$ de altura em material de PVC e são fixados em base de acrílico. Após determinar os tempos de início e fim de pega, através dos resultados das curvas referentes ao NCDTA, foi possível confeccionar as pastas endurecidas e determinar o tempo de desmoldagem das mesmas. Para isso, foram moldados corpos de prova com a relação a/mc de 0,7 , com o teor de $\mathrm{a} / \mathrm{mc}$ acertados pelo ensaio de consistência.

Na curva foi marcada a metade do tempo referente à curva de aceleração da pasta. Com o tempo definido e através de confirmação tátil visual, iniciou-se a desmoldagem de hora em hora para então obter os tempos de desmoldagem para cada teor de substituição.

Em seguida os materiais foram transferidos para uma argamassadeira Varesa modelo 115 , onde foi misturado por 1 minuto em velocidade constante, em seguida transferiu-se para os moldes dos corpos de prova. Após iniciar as moldagens de acordo com a hora para iniciar a carbonatação, os corpos de prova ficaram armazenados em ambiente com umidade $100 \%$.

Após passar o tempo de cura correspondente ao tempo de desmoldagem obtidos pelas curvas de NCDTA, os corpos de prova podem então serem desmoldados e inseridos na câmera de $\mathrm{CO}_{2}$ marca Panasonic modelo COM-18AC-PA e com capacidade de fornecer $10 \%$ de $\mathrm{CO}_{2}$.

Esse procedimento foi aplicado em todos os corpos de prova com a presença de $\mathrm{CO}_{2}$ e no mesmo local sem $\mathrm{CO}_{2}$. O tempo de 1 hora de inserção dos corpos de prova em câmera de $\mathrm{CO}_{2}$ foi determinado a partir da comprovação do trabalho de Neves Junior (2014), que apresenta resultados com 1 hora e 24 horas de carbonatação acelerada. No período de 24 horas, obteve-se queda nas resistências mecânicas dos corpos de prova, submetidos à carbonatação acelerada, diferentemente do período de 1 hora, em que houve ganho de resistência mecânica na presença de $\mathrm{CO}_{2}$.

Em seguida os corpos de prova foram inseridos em cura úmida por 28 dias para então fazer à verificação da resistência a compressão média.

\subsection{Resistências Mecânica à Compressão Simples}

A resistência à compressão simples, denominada fc, é a característica mecânica mais importante de materiais cimentíceos. Para estimá-la, em um lote de concreto, são moldados e preparados corpos-de-prova com as medidas respeitando a relação 2:1, para o ensaio segundo a NBR 7215 Determinação da resistência a compressão (ABNT, 1997).

Os corpos de prova com $5 \mathrm{~cm}$ de altura e $2,5 \mathrm{~cm}$ de diâmetro, foram moldados em duas camadas, adicionando metade da pasta no corpo de prova e com um bastão de vidro adicionavase 12 golpes, finalizava o preenchimento e aplicava-se novamente 12 golpes com o bastão de vidro. Os corpos-de-prova foram mantidos em cura úmida ou saturada até a idade do ensaio, aos 28 dias.

O equipamento utilizado para o rompimento dos corpos-de-prova foi é uma maquina de ensaios universal EMIC modelo DL100T, com uma carga máxima de $1.000 \mathrm{kN}$ e com uma velocidade de $1 \mathrm{~mm} / \mathrm{seg}$.

\subsection{Ensaio de Consistência}

A pasta de consistência normal é definida de acordo com a NBR 16606 (ABNT, 2017), que através do ensaio de Vicat define uma quantidade de água suficiente para atingir uma consistência padrão. Este ensaio foi executado no Laboratório de Materiais de Construção da UFMT. Para este teste foram necessárias quatro tentativas para a pasta controle de cimento 
Portland, três tentativas para a pasta com 10, 20 e 30\% de teor de substituição, obtendo desta forma os resultados para cálculo de porcentagem de água da pasta, obtendo desta forma o índice de consistência normal que é o teor de água necessário para dar a consistência normal à pasta de cimento.

\subsection{Calorimetria}

O ensaio de calorimetria isotérmica foi realizado em calorímetro da marca CALMETRIX modelo I-CAL 2000 HPC ISOTHERMAL CALORIMETER no Laboratório de Estruturas da Faculdade de Arquitetura, Engenharia e Tecnologias (FAET).

Como o calorímetro possui 4 canais, sendo dois para a referência e dois para as pastas analisadas, o ensaio foi realizado em três momentos distintos, comparando as amostras CP2-cont0 com a CP2-D-10\%, CP2-CONT-0 com a CP2-D-20\%, CP2-CONT-0 com a CP2-D-30\%. Todas as pastas utilizadas possuíam relação água/material cimentício determinadas no ensaio de consistência normal. $\mathrm{O}$ ensaio foi realizado em temperatura de $27^{\circ} \mathrm{C}$ e a referência utilizada foi a alumina. O software de aquisição das curvas foi o I-CAL Logger, presente entre os softwares da Calmetrix. Os resultados foram exportados em arquivos de texto (*.txt) para serem tratados no Microsoft Excel $2010^{\circledR}$.

A quantidade de água e cimento e cimento com diatomita, foram pesadas separadamente em frascos plásticos com volume máximo de $125 \mathrm{ml}$, cujas dimensões são próprias para os compartimentos do calorímetro. Em seguida, as amostras foram adicionadas aos frascos que continham água.

As pastas foram misturadas por 30 segundos com o auxílio de uma colher de plástico pequena e depois vedadas nos frascos, juntamente com as colheres, como orienta o fabricante, por meio de uma tampa plástica. Cada frasco foi posicionado no interior do calorímetro nos seus respectivos compartimentos. Por fim, o calorímetro foi vedado para a manutenção da temperatura interna do ensaio, sendo, dessa forma, adiabático.

$\mathrm{O}$ ensaio foi realizado em temperatura de $27^{\circ} \mathrm{C}$ e a referência utilizada foi a alumina. $\mathrm{O}$ software de aquisição das curvas foi o I-CAL Logger, presente entre os softwares da Calmetrix. Os resultados foram exportados em arquivos de texto (.txt) para serem tratados no Microsoft Excel 2010®.

Foram obtidas curvas de energia térmica e de calor de hidratação para os pares CP2-cont-0 com a CP2-D-10\%, CP2-cont-0 com a CP2-D-20\% e CP2-cont-0 com a CP2-D-30\%, monitorados até a idade de 45 horas.

\section{RESULTADOS E DISCUSSÃO}

\subsection{NCDTA}

O NCDTA permitiu definir o tempo de desmoldagem da amostra, pois este ensaio gera uma curva de diferença de temperatura em função do tempo. Por meio da Figura 3 é possível observar esta curva na pasta com teor de substituição de $10 \%$ de diatomita. 
Menegon, Rosane O; Neves Junior, Alex; Estudo do Uso da Carbonatação Acelerada em Pastas de Cimento Portland Usando Resíduos de Diatomita Recuperados. E\&S - Engineering and Science, (2018), 7:1

Figura 3- Curvas do ensaio NCDTA para o teor de $10 \% \mathrm{com} \mathrm{a} / \mathrm{mc}=0,70$.

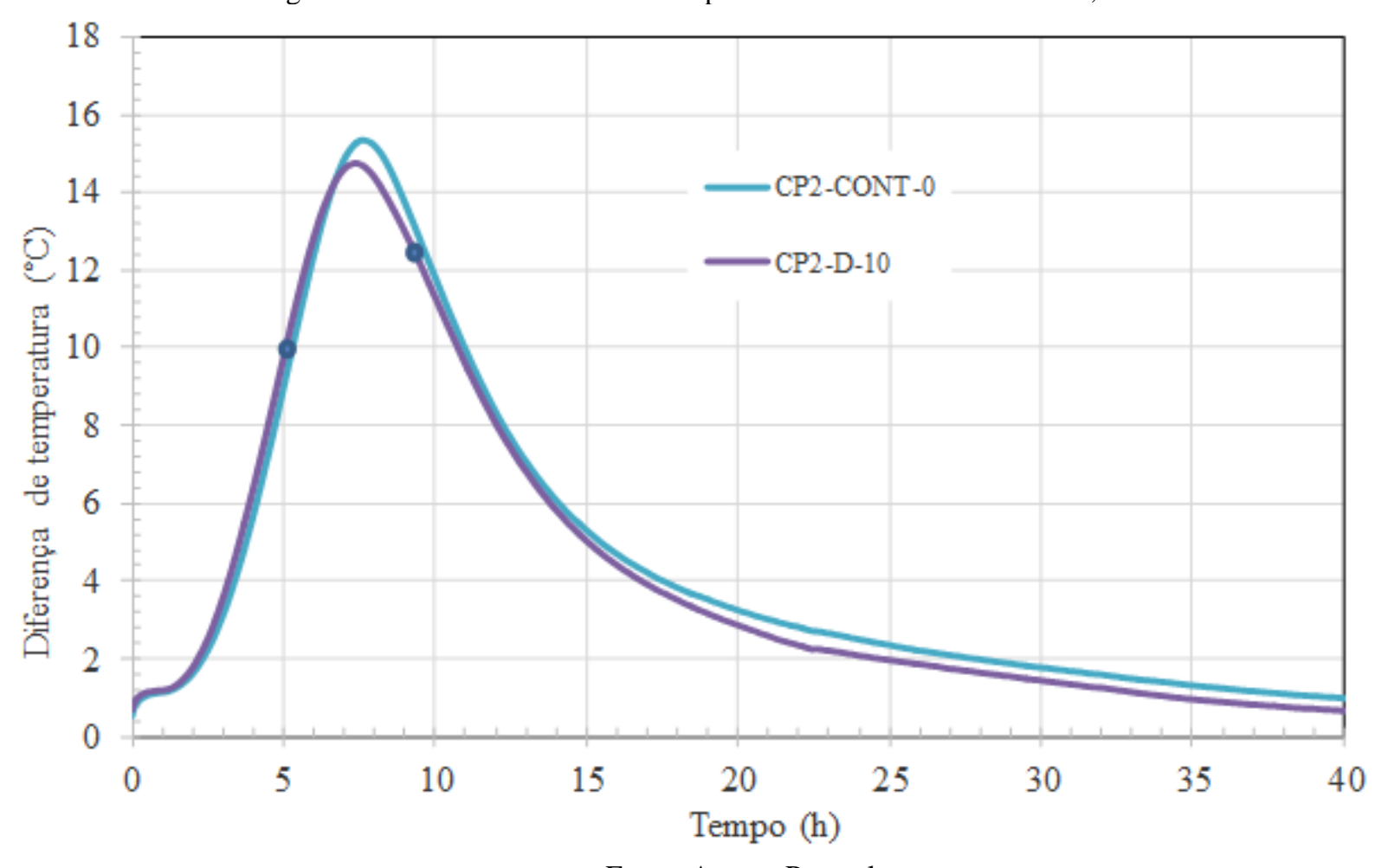

Fonte: Acervo Pessoal

O pico máximo de variação de temperatura registrado pela curva CP2-D-10 não coincide exatamente com o registrado pela curva CP2-CONT-0, sendo o ápice de $\mathrm{t}=7 \mathrm{~h} 15 \mathrm{~min}$ para a amostra com diatomita e $\mathrm{t}=8 \mathrm{~h} 03 \mathrm{~min}$ para a amostra referência. Portanto, a variação de temperatura gerada pelas reações que ocorrem na pasta CP2-CONT-0 chega a ter um valor próximo ao que é gerado pelas reações de hidratação do cimento da pasta CP2-D-10, sendo os valores máximos de diferença de temperatura de $14,66^{\circ} \mathrm{C}$ para a pasta com diatomita e $15,30^{\circ} \mathrm{C}$ para a pasta controle.

Nota-se que o período de indução da pasta CP2-D-10 é mais curto que o mesmo período da pasta CP2-CONT-0 e que ocorre uma aceleração das reações de hidratação nos estágios iniciais. Assim, o período de aceleração da pasta com diatomita se manteve com a mesma duração quando comparado ao mesmo intervalo na pasta CP2-CONT-0.

Com relação Figura 4, nota-se o mesmo comportamento de elevação de temperatura nas pastas com menor teor de substituição e as mesmas com menor tempo de pico de reação de hidratação sendo estes tempos e temperaturas conforme indicados a seguir:

- CP2-D-10: tempo de 6 h 58 min e temperatura $13,41^{\circ} \mathrm{C}$;

- CP2-D-20: tempo de $7 \mathrm{~h} 51$ min e temperatura $8,37^{\circ} \mathrm{C}$;

- CP2-D-30: tempo de $7 \mathrm{~h} 40 \mathrm{~min}$ e temperatura $5,46^{\circ} \mathrm{C}$; e,

- CP2-CONT-0: tempo de $7 \mathrm{~h} 13 \mathrm{~min}$ e temperatura $14,50^{\circ} \mathrm{C}$. 
Menegon, Rosane O; Neves Junior, Alex; Estudo do Uso da Carbonatação Acelerada em Pastas de Cimento Portland Usando Resíduos de Diatomita Recuperados. E\&S - Engineering and Science, (2018), 7:1

Figura 4 Curvas de diferença de temperatura para todos os teores de substituições.

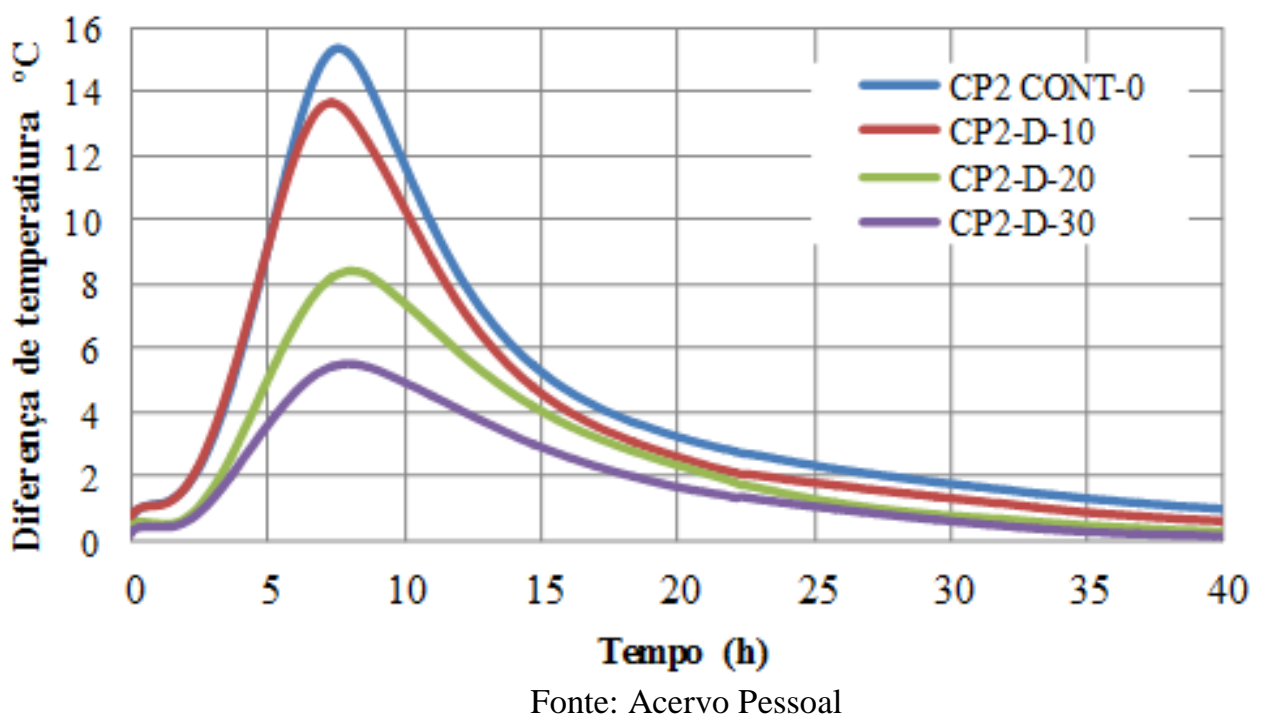

A amostra CP2-D-30 apresenta reações que geram variações de temperatura, chegando a ser $37,66 \%$ menor quando comparada à de referência CP2-CONT-0, que é gerada apenas pelas reações de hidratação do $\mathrm{CP}$.

A pasta CP2-D-10 tem suas reações de hidratação aceleradas, quando comparada às outras pastas. Seu período de indução foi encurtado e a duração de seu período de aceleração se mantém praticamente inalterada, quando comparado ao mesmo período da pasta CP2-CONT-0.

A Figura 5 ilustra a energia acumulada durante as reações de hidratação com o tempo de reação por teor de substituição e relação água/material cimentício.

Figura 5- Curvas de energia acumulada para todos os teores de substituições.

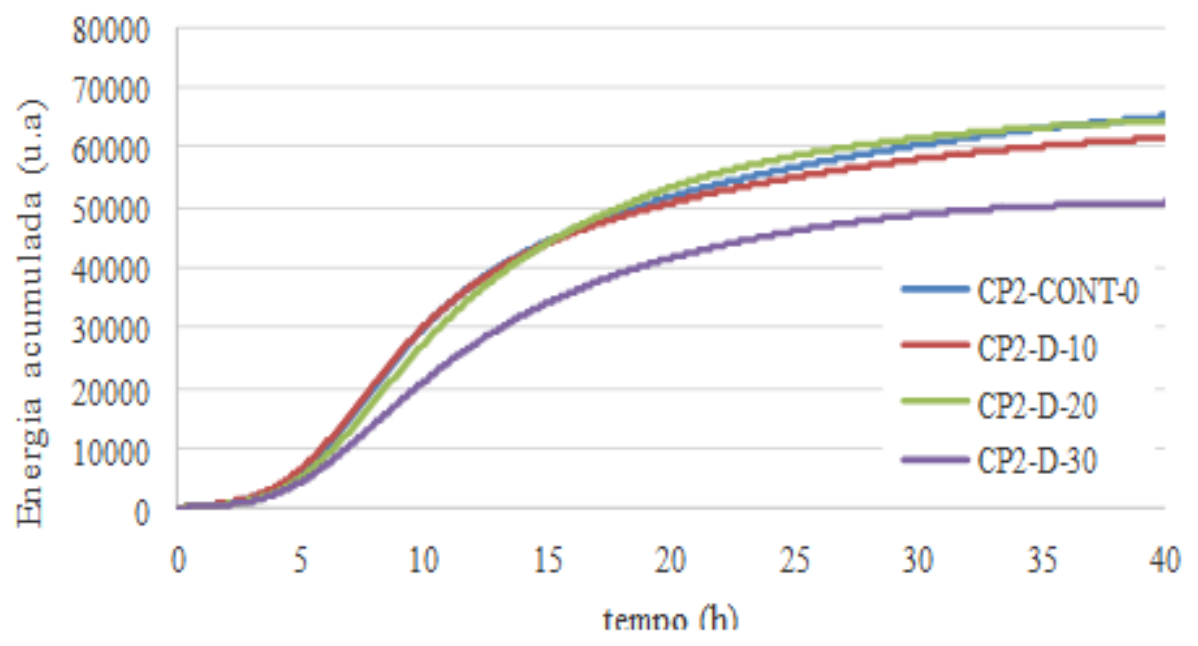

Fonte: Acervo Pessoal.

Nota-se que a mesma energia acumulada em todas as pastas, pode ser obtida até o tempo aproximado de 15 horas, após o início das reações de hidratação. Comparando a diferença de 
energia acumulada entre as amostras CP2-D-10 e CP2-D-20 com a amostra CP2-D-30, nota-se que elas chegam a ser $20,63 \%$ menor.

\subsection{Resistência Mecânica à Compressão Simples}

Após 28 dias de cura controlada, os corpos-de-prova foram então submetidos ao ensaio de compressão axial. De acordo com a Figura 6, é possível verificar elevação da resistência à compressão em virtude da presença de $\mathrm{CO}_{2}$. As elevações mais significativas ocorreram nas pastas com substituição de 10 e 30\%, com elevação média de 66,93 e 67,84\%, respectivamente.

Figura 6 - Valores médios de resistência à compressão simples

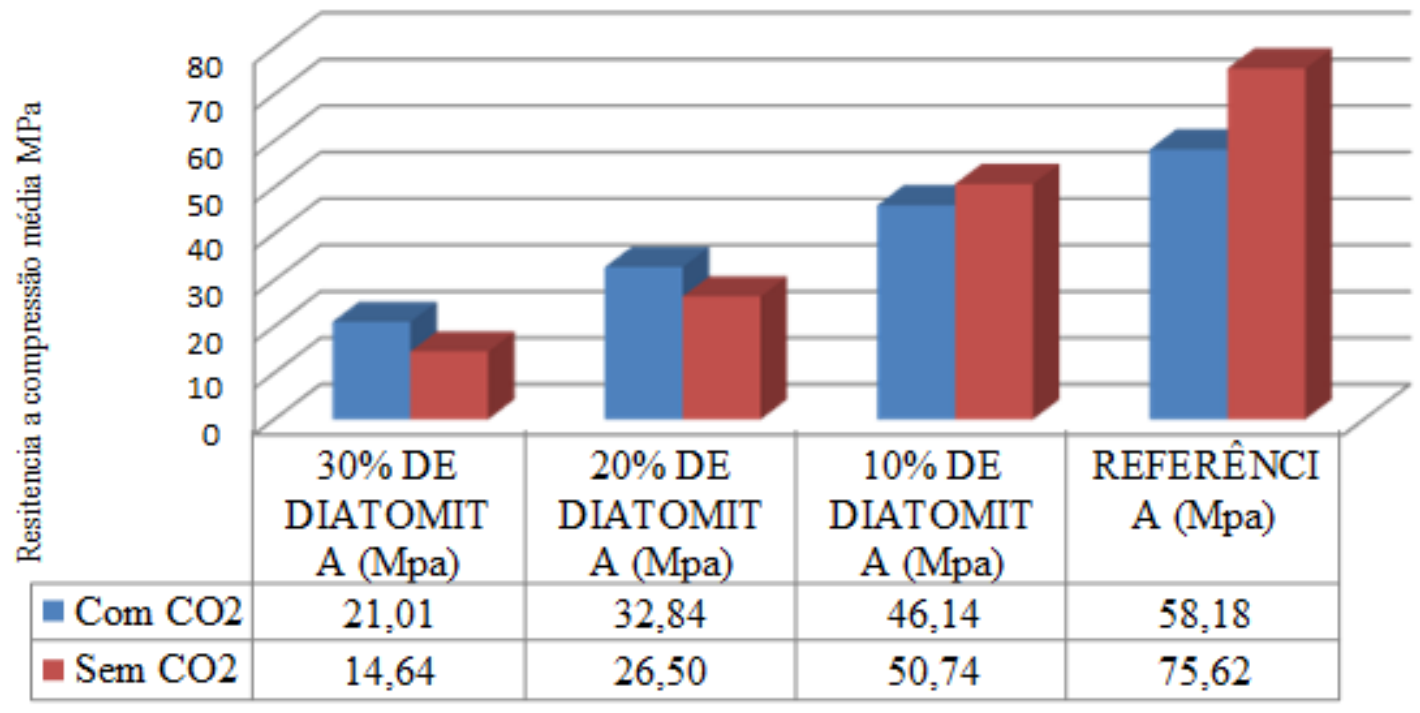

Fonte: Acervo Pessoal.

Portanto, em todas as amostras com presença de diatomita, quando comparadas às referências, obtiveram valores superiores de resistência mecânica. Haja visto que valores maiores de resistência são indicativos de menor porosidade devido à maior formação de produtos durante as reações de hidratação.

\subsection{Determinação Da Relação Agua/ Material Cimentíceo}

Por meio do ensaio consistência foi possível determinar os valores da relação agua/material cimentíceo para cada teor de substituição (Tabela 1).

\begin{tabular}{c|c}
\multicolumn{2}{c}{ Tabela 1- Valores das relações } \\
\hline $\begin{array}{c}\text { Teor de } \\
\text { substituição }\end{array}$ & $\begin{array}{c}\text { Relação } \\
\text { a/mc }\end{array}$ \\
\hline Controle & 0,31 \\
\hline 10 & 0,44 \\
\hline 20 & 0,55 \\
\hline 30 & 0,68 \\
\hline
\end{tabular}

Fonte: Acervo Pessoal. 
Este ensaio teve o objetivo de fazer a correção na consistência e quantidade de água para cada tipo de pasta estudada. Nas pastas com maior teor de substituição, aumentou o consumo de água em virtude da porosidade da diatomita.

No ensaio de resistência a compressão calculou-se os valores encontrados nas amostras com substituição de diatomita após 28 dias de cura, fossem inferiores a amostra controle, indicando que quanto maior o valor a/mc, menor a resistência.

Já na calorimetria a diatomita saturada, retardou a liberação de água nas reações de hidratação, reduzindo desta forma o calor e a energia acumulada.

\subsection{Calorimetria}

O ensaio de calorimetria isotérmica foi executado de acordo com as relações a/mc definidas no ensaio de consistência, obtendo desta forma as curvas de energia térmica e calor de hidratação para cada teor de substituição de diatomita.

Na Figura 7 permite visualizar as curvas de energia térmica de todos os teores de substituição.

Figura 7- Curvas de energia térmica de todos os teores de substituição.

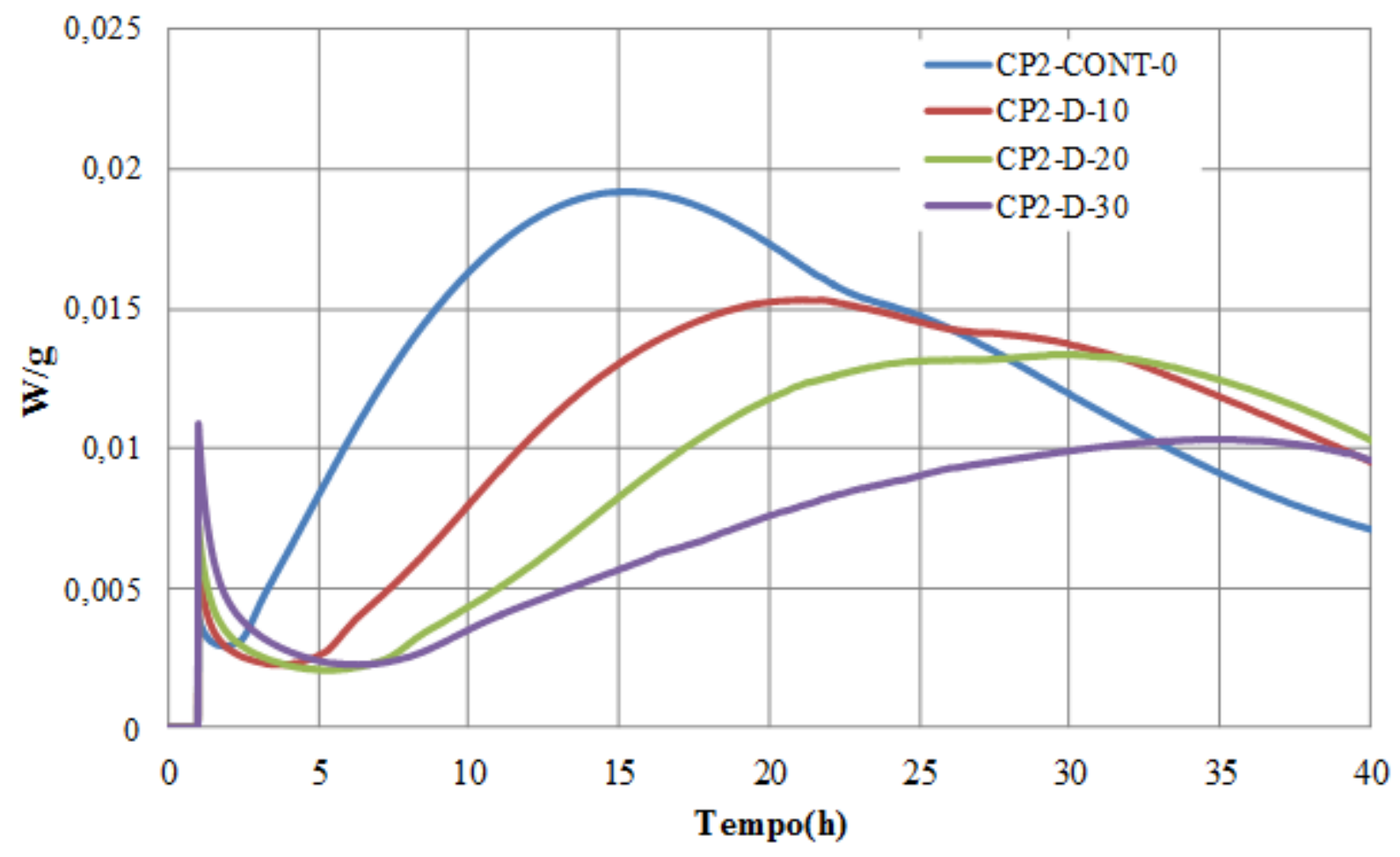

Fonte: Acervo Pessoal.

Nas pastas o aumento de teor de diatomita ocorre um retardamento no calor de hidratação, obtendo desta forma um período maior de indução. Em um período de 10 horas é possível observar que a amostra CP2-D-30 possui 76,47\% menos calor que a pasta controle.

O calor de hidratação normalizado de cada teor de substituição pode ser observado na Figura 8. Em relação as amostras CP2-CONT-0, nota-se que todas as pastas apresentaram redução no calor de hidratação, com percentagens que variaram de 10,52\% no CP2-D-10, 23,68\% para a CP2-D-20 e 39,47\% para CP2-D-30. 
Menegon, Rosane O; Neves Junior, Alex; Estudo do Uso da Carbonatação Acelerada em Pastas de Cimento Portland Usando Resíduos de Diatomita Recuperados. E\&S - Engineering and Science, (2018), 7:1

Figura 8- Curvas de calor de hidratação de todos os teores de substituição

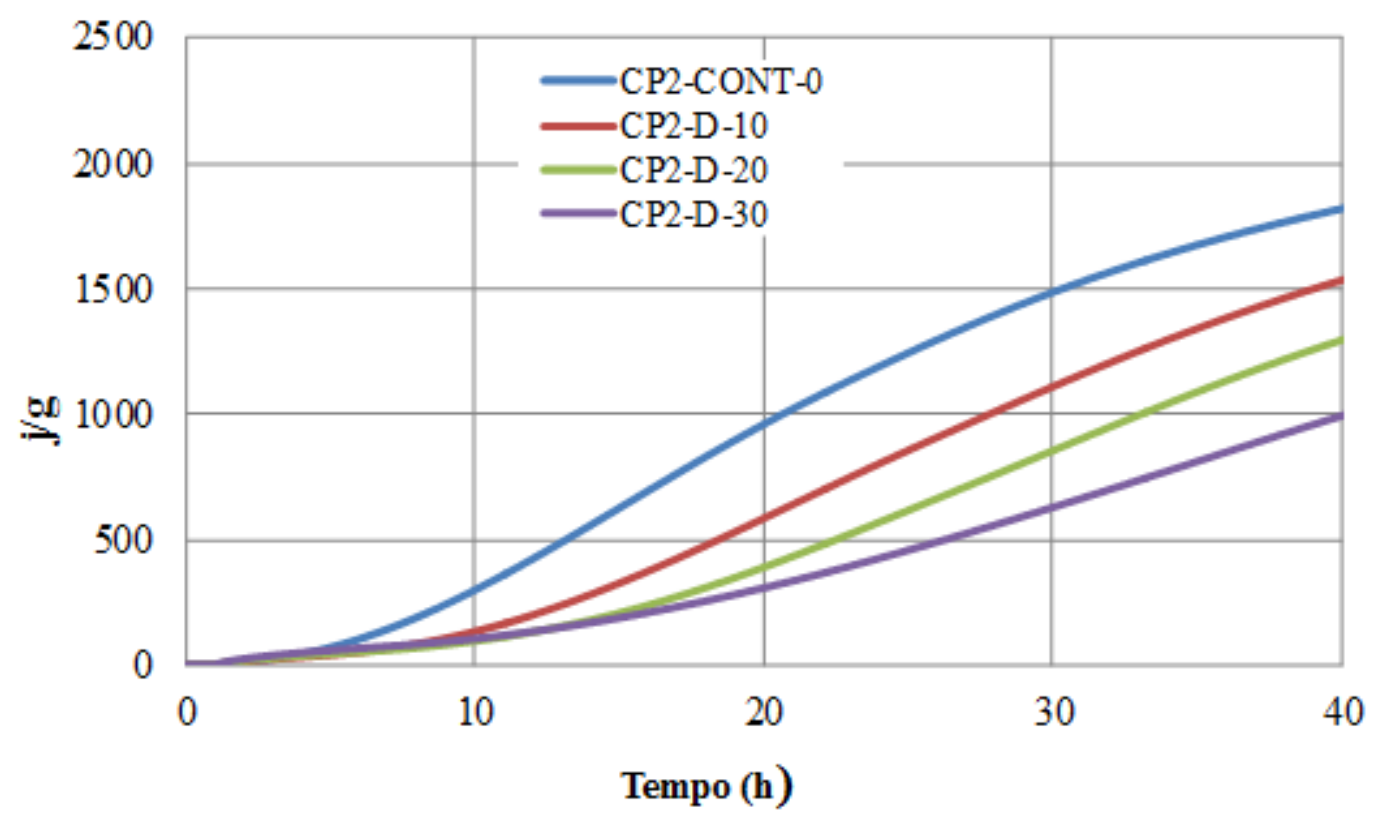

Fonte: Acervo Pessoal.

As pastas com substituição de diatomita apresentaram valor de energia térmica superior ao da pasta controle no período pré-indução, devido a presença da sílica da diatomita. Em função disto, nas primeiras quatro horas, a energia térmica foi superior nas pastas com diatomita e no final das 40 horas, os valores foram superiores nas pastas controle.

Nas quatro horas observa-se uma elevação na curva de calor de hidratação das pastas com substituição de diatomita devido as reações de hidratação ocorridas no período de pré-indução. Passado este período, as curvas de calor de hidratação das pastas controle foram muito superiores aos das curvas com substituição de diatomita. A curva de calor de hidratação é a integração da curva de energia térmica, portanto observa-se que, devido a elevada energia térmica apresentada pelas pastas de controle nos períodos de aceleração, há uma diferença considerável entre as curvas de controle e as curvas com teores de substituição de diatomita.

As curvas normalizadas permitem observar que com a substituição parcial de diatomita nas pastas a base cimento Portland, ocorre uma redução no calor de hidratação em relação a pasta controle.

\section{CONCLUSÃO}

Os resultados obtidos pelas técnicas de análise térmica aplicadas em diversas ensaios de laboratório, permitiu estudar e entender os mecanismos de hidratação das pastas com vários teores de substituição de diatomita.

O ensaio de NCDTA foi de extrema importância para entender o comportamento das pastas e o tempo ideal de desmoldagem para permitir uma maior absorção de $\mathrm{CO}_{2}$ nas pastas em estado fresco.

As referidas análises permitiram estabelecer as condições ideais para captura de $\mathrm{CO}_{2}$ em pastas de cimento Portland sem prejuízo de suas propriedades mecânicas. 
Pastas de cimento Portland, preparadas com relação a/mc=0,7, tratadas com $\mathrm{CO}_{2}$ durante $1 \mathrm{~h}$, com uma concentração de $20 \%$ e $30 \%$, em ambiente com temperatura controlada, obtiveram uma resistência mecânica maior que as amostras sem presença de $\mathrm{CO}_{2}$.

$\mathrm{O}$ ensaio de consistência permite observar que quanto maior o teor de substituição de diatomita, maior a relação a/mc.

As pastas com substituição de diatomita apresentaram um valor de energia térmica superior que as pastas controle devido à presença da sílica da diatomita. Em função disto, nas primeiras 4 horas o calor de hidratação foi superior nas pastas com diatomita devido as reações de hidratação que ocorrem no período de pré-indução e no final das 45 horas as curvas de calor de hidratação das pastas controle foram muito superiores no período de aceleração.

Considerando que este material apresentou condições de ser utilizado na construção civil, o teor de $30 \%$ de substituição de diatomita é o melhor recomendado, pois apresenta características de redução do calor na hidratação das pastas, sendo isso muito importante quanto a retração do concreto. Outro fator é a resistência a compressão que após o tratamento de carbonatação foi superior a amostra controle.

Do ponto de vista ambiental, podemos considerar que este material não é reativo e pode entrar na produção de argamassas, pois a carbonatação acelerada pode prejudicar as armaduras. $\mathrm{O}$ fato de reduzir o impacto ambiental utilizando um resíduo de indústria, pode permitir as construções obterem selos ambientais, tornando a construção civil de certa forma mais sustentável.

\section{AGRADECIMENTOS}

Agradeço o apoio financeiro concedido pela Fundação de Amparo a Pesquisa de Mato Grosso (FAPEMAT).

\section{REFERÊNCIAS}

ASSOCIAÇÃO BRASILEIRA DE NORMAS TÉCNICAS (ABNT), NBR 7181: Solo - Análise granulométrica. Rio de Janeiro, 2016.

ASSOCIAÇÃO BRASILEIRA DE NORMAS TÉCNICAS (ABNT), NBR 7215: Determinação da resistência a compressão. Rio de janeiro, 1996.

ASSOCIAÇÃO BRASILEIRA DE NORMAS TÉCNICAS (ABNT). NBR 16606: Cimento Portland - Determinação da pasta de consistência normal. Rio de Janeiro, 2017.

BREHM, F. A.; Adição de óxido de zinco ( $\mathrm{ZnO})$ em pastas de cimento visando viabilizar a reciclagem de pós de aciaria elétrica (PAE) na construção civil. Tese (Doutorado em Engenharia) - Escola de Engenharia, Universidade Federal do Rio Grande do Sul. Porto Alegre, 2004.

DAMIN; O. C. B. Sequestro de dióxido de carbono $\left(\mathrm{CO}_{2}\right)$ por resíduos de construção e demolição; Dissertação (Mestrado). Programa de Pós-Graduação em Sustentabilidade de Ecossistemas Costeiros e Marinhos à Universidade Santa Cecília, Santos - SP, 2013. 
GOULART; M. R.; SILVEIRA; C. B. D.; CAMPOS; M. L.; ALMEIDA; J. A. D.; COIMBRA; S. M.; OLIVEIRA; A. F. D. Metodologias para reutilização do resíduo de terra diatomácea, proveniente da filtração e clarificação da cerveja. Revista Química Nova, v. 34, n. 4, 2011.

KOUA. S.; ZHANA, B., POON, C. Use of a $\mathrm{CO}_{2}$ curing step to improve the properties of concrete prepared with recycled aggregates. Cement and Concrete Composites. v. 45, p. 22-28, January 2014.

NEVES JUNIOR, A. Captura de $\mathrm{CO}_{2}$ em materiais cimentícios através de carbonatação acelerada. Tese de doutorado. Programa de Pós-Graduação em Engenharia Civil, UFRJ, Rio de Janeiro, Fev. 2014.

NEVES JUNIOR, A.; TOLEDO FILHO;,R. D. D; WECK, J.; FAIRBAIRN, E. D. M. R. A study of $\mathrm{CO} 2$ capture by high initial strength Portland cement pastes at early curing stages by new nonconventional thermogravimetry and non-conventional differential thermal analysis, $\mathbf{J}$ Therm Anal Calorim, V. 129, Issue 3, p.1341-1352, 2017.

RUBERT, S. Contribuição ao estudo de cimentos supersulfatados: formulação e mecanismos de hidratação. Dissertação (Mestrado). Curso de Pós-Graduação em Tecnologia de Processos Químicos e Bioquímicos, Universidade Tecnológica Federal do Paraná, Pato Branco, 2015.

SOBARZO, L. C. D.; MARIN; F. A. D. G. Resíduos Sólidos: Representações, Conceitos e Metodologias: Propostas de Trabalho para o Ensino Fundamental. Revista Ensino Geografia. v. 1, n. 1, p. 3-14, julho/dezembro 2010.

TENÓRIO; J. A. S. ARAÚJO; F. G. D. S. PEREIRA; S. S. R. FERREIRA. A. V. ESPINOSA. D. C. R.; BARROS; A. Decomposição da fase majoritária do cimento Portland - Parte II: alita com adições de Fe e Al. Rev. Esc. Minas, v.56, n.2, 2003.

THOMAS, J.; JENNINGS, H. The Science off concrete; Civil, Architectural and Environmental Engineering, Missouri University of Science and Technology, Columbia, EUA, 2014.

WERLE, A.P,; KAZMIERCZAK, C.S.; KULAKOWSKI, M.P.; Carbonatação em concretos com agregados reciclados de concreto. Ambiente Construído, Porto Alegre, v. 11, n. 2, p. 213-228, 2011. 